Jurnal Indonesia Sosial Teknologi: p-ISSN: 2723 - 6609

e-ISSN : 2548-1398

Vol. 1, No. 4 November 2020

\title{
SISTEM PENDUKUNG KEPUTUSAN PEMILIHAN KARYAWAN BERPRESTASI MENGGUNAKAN METODE AHP DAN TOPSIS : STUDI KASUS PT. TELKOM DIVISI ENTERPRISE SERVICE
}

\author{
Andi Dwi Pangestu \\ Universitas Indraprasta PGRI \\ Email : andi.dwipangestu@gmail.com
}

\section{Abstract}

Determination of outstanding employee at PT. Telkom Enterprise Service Division is done by selecting employees work every part of the field based on predetermined criteria. The criteria used are the skills, knowledge, expertise, flexibility, communication, discipline, responsibility, loyalty and credibility. Problems faced by these companies is how to determine the top performers from a number of alternatives employees. This system is a Decision Support System (DSS), which is built using the merger method of Analytical Hierarchy Process (AHP) and Technique for Order Preference by Similarity to Ideal (TOPSIS) assist the determination of employee achievement. AHP is a decision making method to resolve the problem of determining the selection of the nature multiobjective and methods Technique for Order Preference by Similarity to Ideal Solution (TOPSIS) is a form of method of decision support based on the concept that the best alternative not only has the shortest distance from the ideal solution positive but also has the longest distance from the negative ideal solution. Weighting criteria is done by using AHP and perankingannya done using TOPSIS.

Key Words: AHP, TOPSIS, Decision Support Systems

\begin{abstract}
Abstrak
Penentuan karyawan berprestasi pada PT. Telkom Divisi Enterprise Service dilakukan dengan cara memilih karyawan tiap bagian bidang kerja berdasarkan kriteria yang sudah ditentukan. Kriteria-kriteria yang digunakan adalah keterampilan, pengetahuan, keahlian, fleksibilitas, komunikasi, disiplin, tanggung jawab, loyalitas dan kredibilitas. Masalah yang dihadapi oleh perusahaan tersebut adalah bagaimana menentukan karyawan berprestasi dari sejumlah alternatif karyawan. Metode ini merupakan Sistem Pendukung Keputusan (SPK) yang dibangun dengan menggunakan penggabungan metode Analitycal Hierarchi Process (AHP) dan Technique for Order Preference by Similarity to Ideal (TOPSIS). Hasil dari penelitian, membantu penentuan karyawan berprestasi. AHP merupakan suatu metode pengambilan keputusan untuk menyelesaikan masalah penentuan pilihan yang sifatnya multiobjective dan metode Technique for Order Preference by Similarity to Ideal Solution (TOPSIS) merupakan suatu bentuk metode pendukung keputusan yang didasarkan pada konsep bahwa alternatif yang terbaik tidak
\end{abstract}


hanya memiliki jarak terpendek dari solusi ideal positif tetapi juga memiliki jarak terpanjang dari solusi ideal negatif. Pembobotan kriteria dilakukan dengan menggunakan AHP dan perankingannya dilakukan dengan menggunakan TOPSIS.

Kata kunci: AHP, TOPSIS, Sistem Pendukung Keputusan

\section{Pendahuluan}

Kualitas sumber daya manusia (SDM) ditentukan oleh sejauh mana system sumber daya manusia ini sanggup menunjang dan memuaskan keinginan karyawan maupun perusahaan. Peningkatan pengetahuan, skill, perubahan sikap, prilaku, koreksi terhadap kekurangan-kekurangan kinerja dibutuhkan untuk meningkatkan kinerja dan produktivitas. Karyawan yang memiliki sikap perjuangan, pengabdian, disiplin, dan kemampuan professional sangat mungkin mempunyai prestasi kerja dalam melaksanakan tugas sehingga lebih berdaya guna dan berhasil guna. Karyawan yang professional dapat diartikan sebagai sebuah pandangan untuk selalu berpikir, kerja keras, berkerja sepenuh waktu, disiplin, jujur, loyalitas tinggi dan penuh dedikasi demi untuk keberhasilan pekerjaannya.

Dalam pengolahan data, PT. Telkom terutama Telkom Divisi Enterprise Service bagian SDM, masih ada yang menggunakan spread sheet pada program Microsoft Excel yang terlihat sangat kurang efektif dan efisien.

Dalam hal ini, spread sheet tidak dapat lagi memenuhi syarat ketepatan waktu, kecepatan, dan ketelitian pengelolaan data dalam jumlah yang besar. Sedangkan PT. Telkom Divisi Enterprise Service memiliki banyak karyawan yang harus ditentukan prestasinya dan harus didata pada bagian SDM, yang kesemuanya itu memerlukan waktu yang cukup lama untuk memprosesnya karena harus melihat tabel-tabel dalam bentuk excel yang sangat banyak. Padahal, data-data tersebut digunakan untuk menentukan prestasi karyawan. Hal seperti ini memiliki kerawanan, jika salah memasukan data. Selain itu juga, kurang efektif dalam menentukan prestasi karyawan.

Penelitian ini dilakukan pada PT. Telkom Divisi Enterprise Service. Metode yang akan digunakan dalam penelitian ini adalah metode AHP dan TOPSIS, metode ini dapat memecahkan masalah kompleks, dimana kriteria yang diambil lebih dari satu. Selain itu, metode AHP mempunyai kemampuan untuk memecahkan masalah yang multi objektif dan multi kriteria berdasar perbandingan preferensi dari setiap elemen dalam hierarki. Untuk mengatasi permasalahan di atas, maka perlu dibangun suatu sistem pendukung keputusan dengan menerapkan suatu metode perangkingan

yang dapat mempermudah menentukan karyawan berprestasi dengan menggunakan metode Analytical Hierarchy Process dan Technique For Order Reference by Similarity to Ideal Solution (AHP dan TOPSIS).

TOPSIS menggunakan prinsip bahwa alternatif yang terpilih harus mempunyai jarak terdekat dari solusi ideal positif dan terjauh dari solusi ideal negatif dari sudut 
pandang geometris dengan menggunakan jarak Euclidean untuk menentukan kedekatan relatif dari suatu alternatif dengan solusi optimal.

\section{Metode Penelitian}

Dalam mengambil keputusan sering kali dihadapkan pada berbagai kondisi, antara lain unik, tidak pasti, dinamis jangka panjang dan kompleks. Kondisi unik adalah masalah tersebut tidak mempunyai preseden dan di masa depan mungkin tidak akan berulang kembali. Kondisi tidak pasti adalah faktor-faktor yang diharapkan mempengaruhi dan memiliki kadar informasi sangat rendah. Kondisi jangka panjang memiliki implikasi jangkauan yang cukup jauh ke depan dan melibatkan sumber-sumber usaha yang penting. (Jogiyanto, 2011). Kondisi kompleks, yaitu pengambilan keputusan atas resiko dan waktu memiliki peranan yang besar, komponen dan keterkaitannya sering bersifat dinamik berubah menurut waktu. (Daihan, 2001).

\section{Analitycal Hirarchy Process (AHP)}

Metode AHP dikembangkan oleh Thomas L. Saaty, seorang ahli matematika. Metode ini adalah sebuah kerangka untuk mengambil keputusan dengann efektif atas persoalan yang kompleks dengann menyederhanakan dan mempercepat proses pengambilan keputusan dengan memecahkan persoalan tersebut kedalam bagianbagiannya (Saaty, 1980), menata bagian atau variabel dalam suatu susunan hirarki, memberi nilai numerik pada pertimbangan subjektif tentang pentingnya tiap variabel dan mensintesis berbagai pertimbangan ini untuk menetapkan variabel yang mana yang memiliki prioritas paling tinggi dan bertindak untuk mempengaruhi hasil pada situasi tersebut (Haris, 2015)

\section{Techique For Others Reference by Similarity to Ideal Solution (TOPSIS)}

TOPSIS adalah salah satu metode pengambilan keputusan multikriteria atau alternatif pilihan yang merupakan alternatif yang mempunyai jarak terkecil dari solusi ideal positif dan jarak terbesar dari solusi ideal negatif dari sudut pandang geometris dengan menggunakan jarak Euclidean (Dagdeviren, 2008). Namun, alternatif yang mempunyai jarak terkecil dari solusi ideal positif, tidak harus mempunyai jarak terbesar dari solusi ideal negatif. Maka dari itu, TOPSIS mempetimbangkan keduanya, jarak terhadap solusi ideal positif dan jarak terhadap solusi ideal negative secara bersamaan. Solusi optimal dalam metode TOPSIS didapat dengan menentukan kedekatan relatif suatu altenatif terhadap solusi ideal positif. TOPSIS akan merangking alternatif berdasarkan prioritas nilai kedekatan relatif suatu alternatif terhadap solusi ideal positif. Alternatifalternatif yang telah dirangking kemudian dijadikan sebagai referensi bagi pengambil keputusan untuk memilih solusi terbaik yang diinginkan. (Josowidagdo, 2003)

\section{Hasil dan Pembahasan}

Langkah-langkah perhitungan Topsis sebagai berikut: Menentukan kriteriakriteria yang akan dijadikan acuan dalam pengambilan keputusan dan memberikan bobot penilaian untuk setiap kriteria. Berdasarkan data yang diperoleh dari hasil wawancara di Divisi Enterprise Service di PT. Telkom Indonesia Tbk.. Pada penelitian ini, peneliti 
Sistem Pendukung Keputusan Pemilihan Karyawan Berprestasi Menggunakan Metode AHP dan Topsis : Studi Kasus PT. Telkom Divisi Enterprise Service

mengambil contoh kasus 5 (lima) Staf karyawan yang akan diseleksi untuk menjadi salah satu karawan berprestasi sebagai berikut : A1 =Roni, A2 = Dwi, A3 = Andi, A4 =Alpa.

Tabel 1 Nama kriteria karyawan berprestasi

\begin{tabular}{|c|c|l|}
\hline No. & Kriteria & \multicolumn{1}{|c|}{ Nama Kriteria } \\
\hline 1. & $\mathrm{C} 1$ & Disiplin \\
\hline 2. & $\mathrm{C} 2$ & Fleksibilitas \\
\hline 3. & $\mathrm{C} 3$ & Kredibilitas \\
\hline 4. & $\mathrm{C} 4$ & Keahlian \\
\hline 5. & $\mathrm{C} 5$ & Komunikasi \\
\hline 6. & $\mathrm{C} 6$ & Keterampilan \\
\hline 7. & $\mathrm{C} 7$ & Loyalitas \\
\hline 8. & $\mathrm{C} 8$ & Pengetahuan \\
\hline 9. & $\mathrm{C} 9$ & Tanggung jawab \\
\hline
\end{tabular}

Menentukan nilai perbandingan matriks berpasangan dilakukan dengan metode AHP, sedangkan perangkingan nya dilakukan dengan metode TOPSIS. Membandingkan input data antar kriteria dalam bentuk matriks berpasangan dengan menggunakan skala intensitas kepentingan AHP. Proses ini dilakukan untuk mengetahui nilai konsistensi rasio perbandingan $(\mathrm{CR})$. Dimana syarat $\mathrm{CR}<0.1$.

Tabel 2 Perbandingan Berpasangan Kriteria Mahasiswa Berprestasi

\begin{tabular}{|c|c|c|c|c|c|c|c|c|c|}
\hline & $\mathrm{C} 1$ & $\mathrm{C} 2$ & $\mathrm{C} 3$ & $\mathrm{C} 4$ & $\mathrm{C} 5$ & $\mathrm{C} 6$ & $\mathrm{C} 7$ & $\mathrm{C} 8$ & $\mathrm{C} 9$ \\
\hline $\mathrm{C} 1$ & 1 & 1 & 2 & 5 & 3 & 2 & 3 & 5 & 4 \\
\hline $\mathrm{C} 2$ & $1 / 1$ & 1 & 2 & 5 & 3 & 2 & 3 & 5 & 4 \\
\hline $\mathrm{C} 3$ & $1 / 2$ & $1 / 2$ & 1 & 4 & 2 & 1 & 2 & 4 & 3 \\
\hline $\mathrm{C} 4$ & $1 / 5$ & $1 / 5$ & $1 / 4$ & 1 & $1 / 3$ & $1 / 4$ & $1 / 3$ & 1 & $1 / 2$ \\
\hline $\mathrm{C} 5$ & $1 / 3$ & $1 / 3$ & $1 / 2$ & 3 & 1 & $1 / 2$ & 1 & 3 & 2 \\
\hline $\mathrm{C} 6$ & $1 / 2$ & $1 / 2$ & $1 / 1$ & 4 & 2 & 1 & 2 & 4 & 3 \\
\hline $\mathrm{C} 7$ & $1 / 3$ & $1 / 3$ & $1 / 2$ & 3 & $1 / 1$ & $1 / 2$ & 1 & 3 & 2 \\
\hline $\mathrm{C} 8$ & $1 / 5$ & $1 / 5$ & $1 / 4$ & $1 / 1$ & $1 / 3$ & $1 / 4$ & $1 / 3$ & 1 & $1 / 3$ \\
\hline $\mathrm{C} 9$ & $1 / 4$ & $1 / 4$ & $1 / 3$ & 2 & $1 / 2$ & $1 / 3$ & $1 / 2$ & 2 & 1 \\
\hline
\end{tabular}

Tabel 3: Perbandingan matriks berpasangan kriteria AHP

\begin{tabular}{|c|c|c|c|c|c|c|c|c|c|}
\hline & $\mathrm{C} 1$ & $\mathrm{C} 2$ & $\mathrm{C} 3$ & $\mathrm{C} 4$ & $\mathrm{C} 5$ & $\mathrm{C} 6$ & $\mathrm{C} 7$ & $\mathrm{C} 8$ & $\mathrm{C} 9$ \\
\hline $\mathrm{C} 1$ & 1 & 1 & 2 & 5 & 3 & 2 & 3 & 5 & 4 \\
\hline $\mathrm{C} 2$ & 1 & 1 & 2 & 5 & 3 & 2 & 3 & 5 & 4 \\
\hline $\mathrm{C} 3$ & 0.5 & 0.5 & 1 & 4 & 2 & 1 & 2 & 4 & 3 \\
\hline $\mathrm{C} 4$ & 0.2 & 0.2 & 0.25 & 1 & 0.33 & 0.25 & 0.33 & 1 & 0.5 \\
\hline $\mathrm{C} 5$ & 0.33 & 0.33 & 0.5 & 3 & 1 & 0.5 & 1 & 3 & 2 \\
\hline $\mathrm{C} 6$ & 0.5 & 0.5 & 1 & 4 & 2 & 1 & 2 & 4 & 3 \\
\hline $\mathrm{C} 7$ & 0.33 & 0.33 & 0.5 & 3 & 1 & 0.5 & 1 & 3 & 2 \\
\hline $\mathrm{C} 8$ & 0.2 & 0.2 & 0.25 & 1 & 0.33 & 0.25 & 0.33 & 1 & 0.5 \\
\hline $\mathrm{C} 9$ & 0.25 & 0.25 & 0.33 & 2 & 0.5 & 0.33 & 0.5 & 2 & 1 \\
\hline jumlah & $\mathbf{4 . 3 2}$ & $\mathbf{4 . 3 2}$ & $\mathbf{7 . 8 3}$ & $\mathbf{2 8 . 0 0}$ & $\mathbf{1 3 . 1 7}$ & $\mathbf{7 . 5 3}$ & $\mathbf{1 3 . 1 7}$ & $\mathbf{2 8 . 0 0}$ & $\mathbf{2 0 . 0 0}$ \\
\hline
\end{tabular}

Dari matriks perbandingan diatas, maka dapat dihitung nilai eigen, lamda maksimum, dan CR. Sebelum menghitung nilai eigen, dicari nilai perbandingan pada tiap kolom dibagi dengan jumlah kolomnya, seperti di bawah ini. 
Tabel 4 Nilai perbandingan tiap kolom dibagi jumlah kolom

\begin{tabular}{|c|c|c|c|c|c|c|c|c|c|}
\hline & $\mathrm{C} 1$ & $\mathrm{C} 2$ & $\mathrm{C} 3$ & C4 & C5 & C6 & $\mathrm{Cl}$ & $\mathrm{Cs}$ & C9 \\
\hline $\mathrm{Cl}$ & 0.232 & 0.232 & 0.255 & 0.179 & 0.228 & 0.255 & 0.228 & 0.179 & 0.201 \\
\hline $\mathrm{C}_{2}$ & 0.232 & 0.232 & 0.255 & 0.179 & 0.228 & 0255 & 0.228 & 0.179 & 0201 \\
\hline c3 & 0.116 & 0.116 & 0.128 & 0.143 & 0.152 & 0.123 & 0.152 & 0.143 & 0.154 \\
\hline C4 & 0.046 & 0.046 & 0.032 & 0.036 & 0.025 & 0.032 & 0.025 & 0.036 & 0.025 \\
\hline C5 & 0.077 & 0.077 & 0.064 & 0.107 & 0.076 & 0.064 & 0.076 & 0.107 & 0.101 \\
\hline$\alpha$ & 0.116 & 0.116 & 0.128 & 0.143 & 0.152 & 0.123 & 0.152 & 0.143 & 0.194 \\
\hline C7 & 0.077 & 0.077 & 0.064 & 0.107 & 0.076 & 0.064 & 0.076 & 0107 & 0.101 \\
\hline $\mathrm{Cs}$ & 0.046 & 0.046 & 0.032 & 0.036 & 0.025 & 0.032 & 0.023 & 0.036 & 0.025 \\
\hline 9 & 0.058 & 0.058 & 8.043 & 0.971 & 0.038 & 0.043 & 0.038 & 0.071 & 0.054 \\
\hline jumlab & 1.600 & 1.010 & 1.060 & 1.000 & 1.610 & 1.000 & 1.600 & 1.000 & 1006 \\
\hline
\end{tabular}

Setelah diperoleh hasil pembagian tiap kolomnya, maka dapat dihitung nilai eigen, yaitu dengan menjumlahkan nilai-nilai dari setiap baris dan membaginya dengan banyak elemen kriteria untuk mendapatkan rata-rata. Seperti nilai eigen untuk baris kriteria pertama $(\mathrm{C} 1)$ dan hasil penjumlahan nilai eigen akan selalu bernilai satu.

Tabel 5 Nilai eigen kriteria

\begin{tabular}{|c|c|c|c|c|c|c|c|c|c|c|}
\hline & C1 & C2 & C3 & C4 & C5 & C6 & C7 & C8 & C9 & eigen \\
\hline C1 & 0.232 & 0.232 & 0.255 & 0.179 & 0.228 & 0.255 & 0.228 & 0.179 & 0.200 & 0.221 \\
\hline C2 & 0.232 & 0.232 & 0.255 & 0.179 & 0.228 & 0.255 & 0.228 & 0.179 & 0.200 & 0.221 \\
\hline C3 & 0.116 & 0.116 & 0.128 & 0.143 & 0.152 & 0.128 & 0.152 & 0.143 & 0.150 & 0.136 \\
\hline C4 & 0.046 & 0.046 & 0.032 & 0.036 & 0.025 & 0.032 & 0.025 & 0.036 & 0.025 & 0.034 \\
\hline C5 & 0.077 & 0.077 & 0.064 & 0.107 & 0.076 & 0.064 & 0.076 & 0.107 & 0.100 & 0.083 \\
\hline C6 & 0.116 & 0.116 & 0.128 & 0.143 & 0.152 & 0.128 & 0.152 & 0.143 & 0.150 & 0.136 \\
\hline C7 & 0.077 & 0.077 & 0.064 & 0.107 & 0.076 & 0.064 & 0.076 & 0.107 & 0.100 & 0.083 \\
\hline C8 & 0.046 & 0.046 & 0.032 & 0.036 & 0.025 & 0.032 & 0.025 & 0.036 & 0.025 & 0.034 \\
\hline C9 & 0.058 & 0.058 & 0.043 & 0.071 & 0.038 & 0.043 & 0.038 & 0.071 & 0.050 & 0.052 \\
\hline jumlah & $\mathbf{1 . 0 0 0}$ & $\mathbf{1 . 0 0 0}$ & $\mathbf{1 . 0 0 0}$ & $\mathbf{1 . 0 0 0}$ & $\mathbf{1 . 0 0 0}$ & $\mathbf{1 . 0 0 0}$ & $\mathbf{1 . 0 0 0}$ & $\mathbf{1 . 0 0 0}$ & $\mathbf{1 . 0 0 0}$ & $\mathbf{1 . 0 0 0}$ \\
\hline
\end{tabular}

Setelah diperoleh nilai eigen kriterianya, maka dihitung nilai lamda maksimum ( $\lambda$ maks), yaitu dapat dihitung dengan menjumlahkan hasil dari perkalian nilai eigen dengan jumlah kolom.

$\lambda$ maks $=\left(\begin{array}{ll}0.221 & 4.32\end{array}\right)+\left(\begin{array}{ll}0.221 & 4.32\end{array}\right)+\left(\begin{array}{ll}0.136 & 7.83\end{array}\right)+\left(\begin{array}{ll}0.034 & 28\end{array}\right)+\left(\begin{array}{ll}0.083 & 13.17\end{array}\right)+$ $(0.1367 .83)+(0.08313 .17)+(0.03428)+(0.05220) / 9=9.16294 / 9=1.018109$

Dihitung CI dengan persamaan dengan $\mathrm{n}=9$ karena banyak kriterianya ada 9.

$$
\mathrm{CI} \quad=\frac{1.018105-9}{8}=-0.9977
$$

Setelah dapat nilai CI , kemudian hitung nilai CR. Nilai RI untuk $\mathrm{n}=9$ adalah 1.45 , sehingga

$$
\begin{aligned}
\mathrm{CR}= & =\frac{-0.9977}{1.45}=-0.6881 \\
& =\mathbf{- 0 . 6 8 8 1} \text { (konsisten karena memenuhi syarat } \mathbf{C R}<\mathbf{0 . 1}) .
\end{aligned}
$$

Jika nilai $C R \geq 0.1$ maka tidak konsisten atau tidak memenuhi syarat dan diulang kembali matriks perbandingan hingga nilai CR nya memenuhi syarat yang telah ditentukan. Dari tabel nilai alternative tersebut, didapat nilai perbandingan matriks berpasangan.

Berikut ini tabel perbandingan matriks berpasangan alternative terhadap 9 kriteria yang telah ditentukan perusahaan tersebut. Tabel 1 Perbandingan matriks berpasangan alternatif untuk kriteria . 
Sistem Pendukung Keputusan Pemilihan Karyawan Berprestasi Menggunakan Metode AHP dan Topsis : Studi Kasus PT. Telkom Divisi Enterprise Service

Tabel 6 Matriks bobot alternatif terhadap kriteria

\begin{tabular}{|c|c|c|c|c|c|c|c|c|c|}
\hline & $\mathbf{C 1}$ & $\mathbf{C 2}$ & $\mathbf{C 3}$ & $\mathbf{C 4}$ & $\mathbf{C 5}$ & $\mathbf{C 6}$ & $\mathbf{C 7}$ & $\mathbf{C 8}$ & $\mathbf{C 9}$ \\
\hline $\mathbf{A 1}$ & 0.079 & 0.519 & 0.097 & 0.300 & 0.389 & 0.097 & 0.555 & 0.389 & 0.125 \\
\hline $\mathbf{A 2}$ & 0.201 & 0.201 & 0.252 & 0.100 & 0.153 & 0.252 & 0.252 & 0.153 & 0.375 \\
\hline $\mathbf{A 3}$ & 0.519 & 0.201 & 0.097 & 0.300 & 0.069 & 0.097 & 0.097 & 0.069 & 0.125 \\
\hline $\mathbf{A 4}$ & 0.201 & 0.079 & 0.555 & 0.300 & 0.389 & 0.555 & 0.097 & 0.389 & 0.375 \\
\hline
\end{tabular}

Setelah memperoleh nilai eigen kriteria dan nilai eigen alternatif, kemudian dilanjutkan dalam perhitungan TOPSIS. Matriks keputusan yang dihasilkan dari metode AHP merupakan modal awal dalam perhitungan TOPSIS. Matriks bobot alternative terhadap kriteria merupakan matriks ternormalisasi pada metode TOPSIS.

Tabel 7 Matriks ternormalisasi

\begin{tabular}{|c|c|c|c|c|c|c|c|c|c|}
\hline & C1 & C2 & $\mathrm{C} 3$ & $\mathrm{C} 4$ & $\mathrm{Cs}$ & $\mathrm{Cb}$ & C. & $C 8$ & $\mathrm{Cs}$ \\
\hline $\begin{array}{c}\text { Eigen } \\
\text { Kriteria }\end{array}$ & 0.221 & 0.221 & 0.136 & 0.034 & 0.683 & 0.156 & 0.963 & e.04 & a.ost \\
\hline $\mathbf{A 1}$ & 0.079 & 0.519 & 0.097 & 0.300 & 0.389 & 0.097 & 0.555 & 0.369 & 0.125 \\
\hline $\mathbf{A 2}$ & 0.201 & 0.201 & 0.252 & 0.100 & 0.153 & 0.252 & 0.252 & 0.153 & 0.375 \\
\hline 13 & 0.519 & 0.201 & 0007 & 0.300 & 0.069 & 0.007 & 0.097 & 0.060 & 0.125 \\
\hline $\mathbf{M}$ & 0.201 & 0.079 & 0.555 & 0.300 & 0.389 & 0.555 & 0.097 & 0.359 & 0.375 \\
\hline
\end{tabular}

Menyusun matriks ternormalisasi terbobot dengan cara matriks bobot alternative terhadap kriteria dari pengolahan AHP dikalikan dengan eigen dari kriteria.

Tabel 8 Matriks ternormalisasi terbobot

\begin{tabular}{|c|c|c|c|c|c|c|c|c|c|}
\hline & C1 & C2 & C3 & C4 & C5 & C6 & C7 & C8 & C9 \\
\hline A1 & 0.017 & 0.115 & 0.013 & 0.010 & 0.032 & 0.013 & 0.046 & 0.013 & 0.007 \\
\hline $\mathbf{A 2}$ & 0.044 & 0.044 & 0.034 & 0.003 & 0.013 & 0.034 & 0.021 & 0.005 & 0.020 \\
\hline $\mathbf{A 3}$ & 0.115 & 0.044 & 0.013 & 0.010 & 0.006 & 0.013 & 0.008 & 0.002 & 0.007 \\
\hline $\mathbf{A 4}$ & 0.044 & 0.017 & 0.076 & 0.010 & 0.032 & 0.076 & 0.008 & 0.013 & 0.020 \\
\hline
\end{tabular}

Dari matriks keputusan ternormalisasi terbobot diatas dapat ditentukan titik ideal positif dan titik ideal negative.

Tabel 9 Titik ideal positif dan titik ideal negative

\begin{tabular}{|c|c|c|}
\hline Kriteria & A+ & A- \\
\hline C1 & 0.115 & 0.017 \\
\hline C2 & 0.115 & 0.017 \\
\hline C3 & 0.076 & 0.013 \\
\hline C4 & 0.010 & 0.003 \\
\hline C5 & 0.032 & 0.006 \\
\hline C6 & 0.076 & 0.013 \\
\hline C7 & 0.046 & 0.008 \\
\hline C8 & 0.013 & 0.002 \\
\hline C9 & 0.020 & 0.007 \\
\hline
\end{tabular}

Setelah didapat titik ideal positif dan titik ideal negatif dari table perkalian matriks alternatif terhadap kriteria dan nilai eigen kriteria lalu tentukan separation measures atau jarak setiap alternatif terhadap titik ideal positif dan titik ideal negatif. Untuk menghitung jarak setiap alternatif terhadap titik ideal positif dan negatif.

Tabel 10 Jarak antara alternatif solusi ideal positif dan solusi ideal negative

\begin{tabular}{|c|c|c|}
\hline Alternatif & D+ & D- \\
\hline $\mathbf{A 1}$ & 0.132 & 0.109 \\
\hline $\mathbf{A 2}$ & 0.120 & 0.052 \\
\hline $\mathbf{A 3}$ & 0.123 & 0.101 \\
\hline $\mathbf{A 4}$ & 0.126 & 0.098 \\
\hline
\end{tabular}

Jurnal Indonesia Sosial Teknologi, Vol. 1, No. 4, November 2020 
Setelah dapat nilai jarak antara alternatif solusi ideal positif dan solusi ideal negatif, langkah selanjutnya menghitung nilai kedekatan relative. Nilai kedekatan relative (preferensi) inilah yang menentukan perangkingan karyawan mana yang berprestasi.

$$
\begin{aligned}
& V_{1}=\frac{0.109}{0.109+0.132}=\frac{0.109}{0.241}=0.4512 \\
& V_{2}=\frac{0.052}{0.052+0.120}=\frac{0.052}{0.172}=0.303 \\
& V_{3}=\frac{0.101}{0.101+0.123}=\frac{0.101}{0.224}=0.4507 \\
& V_{4}=\frac{0.098}{0.098+0.126}=\frac{0.098}{0.224}=0.437
\end{aligned}
$$

Dari nilai V di atas dapat disimpulkan bahwa alternatif (A1) memiliki nilai bobot yang paling optimum dibandingkan dengan alternatif lain. Oleh karena itu,dapat diambil keputusan bahwa A1 yang terpilih menjadi karyawan berprestasi di divisi Enterprise Service.

\section{Implementasi}

Perancangan antar muka sistem bertujuan untuk menggambarkan sistem yang akan dibuat. Menu utama dari aplikasi ini berisi menu Akun, data master, penilaian, AHPTOPSIS, dan laporan keputusan. Pada menu utama ini juga berisi informasi tentang tujuan dari pembuatan sistem dan bagaimana cara penggunaan sistem.

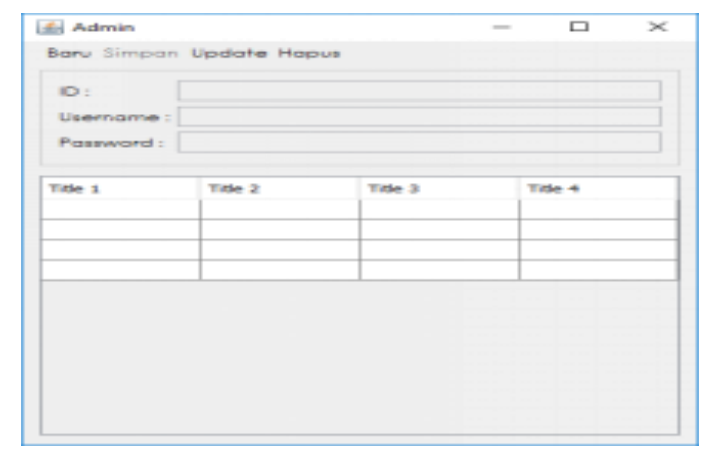

\section{Gambar 3 Tampilan Menu Login}

Pada gambar 4, merupakan form untuk menilai karyawan berdasarkan tiap-tiap kriterianya. Misalkan karyawan yang bernama andi, kriterianya adalah kualitas kerja, dan nilainya sangat bagus. 


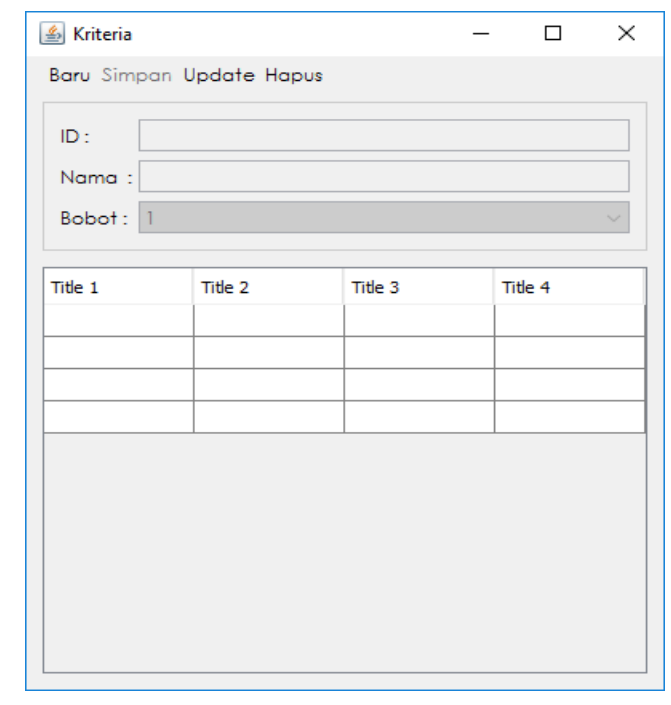

\section{Gambar 4 Tampilan Menu Kriteria}

Setelah sistem dirancang dengan sesuai kebutuhan user, maka dipersiapkan infrastruktur yaitu Hardware dan Software, lalu dilakukan instalasi pada hardware dan software yang menunjang pemasangan sistem penunjang keputusan. Selanjutnya dibuatkan user manual untuk mempermudah user dalam menggunakan sistem. Dilakukan tahap pengujian terhadap sistem yang tujuannya untuk menemukan jika terdapat kesalahan pada sistem. Saran dan masukan dari hasil pengujian akan diperbaiki. Setelah dilakukan perbaikan maka akan dilaksanakan pelatihan dengan user terkait agar nantinya sistem yang dipakai sesuai dengan harapan. Setelah dilakukan tahap testing maka terlebih dahulu sistem di uji coba dengan jangka waktu yang telah ditentukan lalu laporan dari evaluasi sistem yang telah diuji coba akan diperbaiki yang hasil dari perbaikan tersebut akan diterapkan pada sistem sebenarnya.

\section{Kesimpulan}

Setelah melalui tahap pengujian pada sistem pendukung keputusan pemilihan karyawan berprestasi, di dapatkan kesimpulan bahwa :

Pemilihan karyawan berprestasi dapat dilakukan dengan menggunakan penggabungan metode AHP dan metode TOPSIS yang memiliki nilai keakuratan yang lebih baik daripada menggunakan perhitungan manual.

Aplikasi Sistem Pendukung Keputusan Pemilihan Karyawan Berprestasi ini telah berhasil dibangun untuk PT. Telkom Divisi Enterprise Service dalam pemilihan karyawan berprestasi untuk menghasilkan keputusan yang lebih objektif,terkomputerisasi dan mengurangi terjadinya human error. 


\section{Bibliografi}

Dagdeviren, M. (2008). Weapon Selection Using the AHP and TOPSIS Methods Under Fuzzy Environment.

Daihan, D. U. (2001). Komputerisasi Pengambilan Keputusan Berbasis Komputer. Jakarta: PT. Elex Media Komputindo.

Haris, A. D. (2015). Perancangan dan pembuatan Aplikasi Sistem Pendukung Keputusan Pemilihan Karyawan Berprestasi Berdasarkan Kinerja Menggunakan Metode AHP” Sistem Informasi. Universitas Sriwijaya.

Himmah, F. U. (n.d.). Implementasi metode AHP TOPSIS dalam perangkingan Prioritas Pengerjaan Order dan Penentuan Lintasan Kritis dengan Fuzzy Pert. Teknik Industri ITS.

Jogiyanto, H. (2011). Analisa dan Desain Sistem Informasi. Jogyakarta: Andi.

Josowidagdo, L. (2003). Metode TOPSIS sebagai Penentu Prioritas Alternatif Keputusan Program Transportasi.

Kardi Teknomo, H. S. (1999). Penggunaan Metode Analytic Hierarchy Process Dalam Menganalisa Faktor-faktor yang Mempengaruhi Pemilihan Moda ke Kampus. Jakarta.

Kusrini. (2007). Konsep dan Aplikasi Sistem Pendukung Keputusan. Yogyakarta: Andi.

Pressman, S. R. (2005). Software Engineering. New York: McGrow-Hill.

Ragawanti, E. S. (2014). Pengaruh On The Job Training \& Off The Job Training Terhadap Kinerja Karyawan. Universitas Brawijaya.

Saaty, T. L, . (1993). Pengambilan Keputusan Bagi Para Pemimpin Proses Hirarki. Binama Pressindo.

Saaty, T. L. (1980). The Analytic Hierarchy Process. New York: McGraw- Hill.

Shih, H. S. (2001). An Extension of TOPSIS for Group Decision Making. Taiwan.

Subakti, I. (2002). Sistem Pendukung Keputusan. ITS.

Suhaedi, D. (2006). Penggunaan metode topsis . UNISBA.

Suryadi, K. D. (2000). Sistem Pendukung Keputusan. PT. Remaja Rosdakarya. 